\title{
GROWTH AND COLLOID HYDRATATION IN CACTI
}

\author{
ESMOND R. LONG
}

\section{(WITH TWO FIGURES)}

During the growing season of I9I4 (March to August), attempts were made to correlate growth rates of cacti in solutions of varying reaction and concentration with the hydratation phenomena exhibited on placing cut pieces of the same species in similar solutions.

It was thought at first that the parallelism discovered by BorowiKow $^{\mathrm{I}}$ in the growth rate and hydratation of Helianthus annuus might be expressive of a general property of plant colloids. This investigator found that acidity is a favoring factor in both the growing and the swelling rate of Helianthus, the amount of swelling and the amount of acceleration of growth being dependent upon the concentration of the acid, and differing with different acids, and that alkalies increase swelling and to a greater extent than acids, but do not appreciably affect growth. DAcHNowsKI ${ }^{2}$ has obtained somewhat parallel results on the effect of acid with beans.

Experiments of a similar nature were performed in this laboratory upon Opuntia Blakeana, hydrochloric and malic acids (the latter being the acid existing in greatest concentration in the sap) being used as standards for the effect of acid, and sodium hydroxide as the standard for the effect of alkali. Growth rate and swelling were studied also in a nutrient solution made by diluting to I roo cc. Ioo cc. of the following solution: calcium nitrate $6 \mathrm{gm}$., potassium nitrate I.5 gm., magnesium sulphate I. 5 gm., potassium monohydrogen phosphate I. 5 gm., sodium chloride I.5 gm., and distilled water $600 \mathrm{cc}$.

For the experiments on growth, joints of O. Blakeana matured in $\mathrm{I}_{\mathrm{I}} 3$, bearing a small flower bud or new joint, were used, the old

I Borowikow, G. A., Biochem. Zeitschr. 48:230-246; and 50:119-128. I913.

2 Dachnowski, A., Amer. Jour. Bot. I:4I 2-439. I9I4.

[Botanical Gazette, vol. 59 
joint being cut off smoothly at the base and placed in the appropriate solution, the latter being replaced by freshly prepared solution every few days. All the plants were suspended by means of wooden clamps in the various solutions to a uniform depth of $5 \mathrm{~cm}$., and the battery jars containing the preparations were exposed to full sunlight in the laboratory court. While temperature and light conditions were thus not controlled, they were the same for all of the plants. The length of the new joint or bud was then measured at intervals of 3 or 4 days. In the swelling experiments, sections of standard size from healthy plants were cut with a cork borer, weighed, immersed in the different media, and kept in the dark in the laboratory constant-temperature room, the imbibed water being determined by weighing at 6-hour intervals during the following 24 hours. Inasmuch as there is considerable individual variation in swelling power in different joints from the same species, in all cases the experiments were conducted in such a way that all the joints used had equal representation in all the solutions of that experiment.

It developed immediately that for Opuntia Blakeana, with the concentrations of acid which it was practical to use with this plant, which has a concentration varying between $\mathrm{N} / \mathrm{ro}$ and $\mathrm{N} / 20$ in its own sap, the observations recorded above for Helianthus do not hold. The results of these experiments are summed up in figs. I and 2 and table I, growth increment being expressed in millimeters,

TABLE I

GROWTH OF FLOWER BUDS OF Opuntia Blakeana, MARCH 25-APRIL 24

\begin{tabular}{|c|c|c|}
\hline Medium & $\begin{array}{c}\text { Total growth } \\
\text { increment } \\
\text { before flowering }\end{array}$ & Time in days \\
\hline 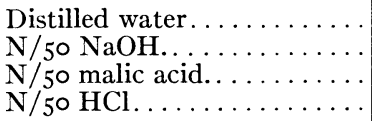 & $\begin{array}{l}42.0 \mathrm{~mm} . \\
40.5 \\
36.0 \\
31.0\end{array}$ & $\begin{array}{l}27 \\
30 \\
28 \\
28\end{array}$ \\
\hline
\end{tabular}

and swelling in percentage of the original weight. In nearly all cases the recorded figures represent the average for a number of plants, all of the hydratation experiments being carried out at least four times, and the majority of them twelve times. 
The most striking fact brought out by the experiments is the inhibiting effect of acids upon both growth and hydratation, quite the opposite result from that obtained by Borowikow with Helianthus. The discrepancy may be due in part to the stronger concentrations used in the experiment with Opuntia Blakeana,

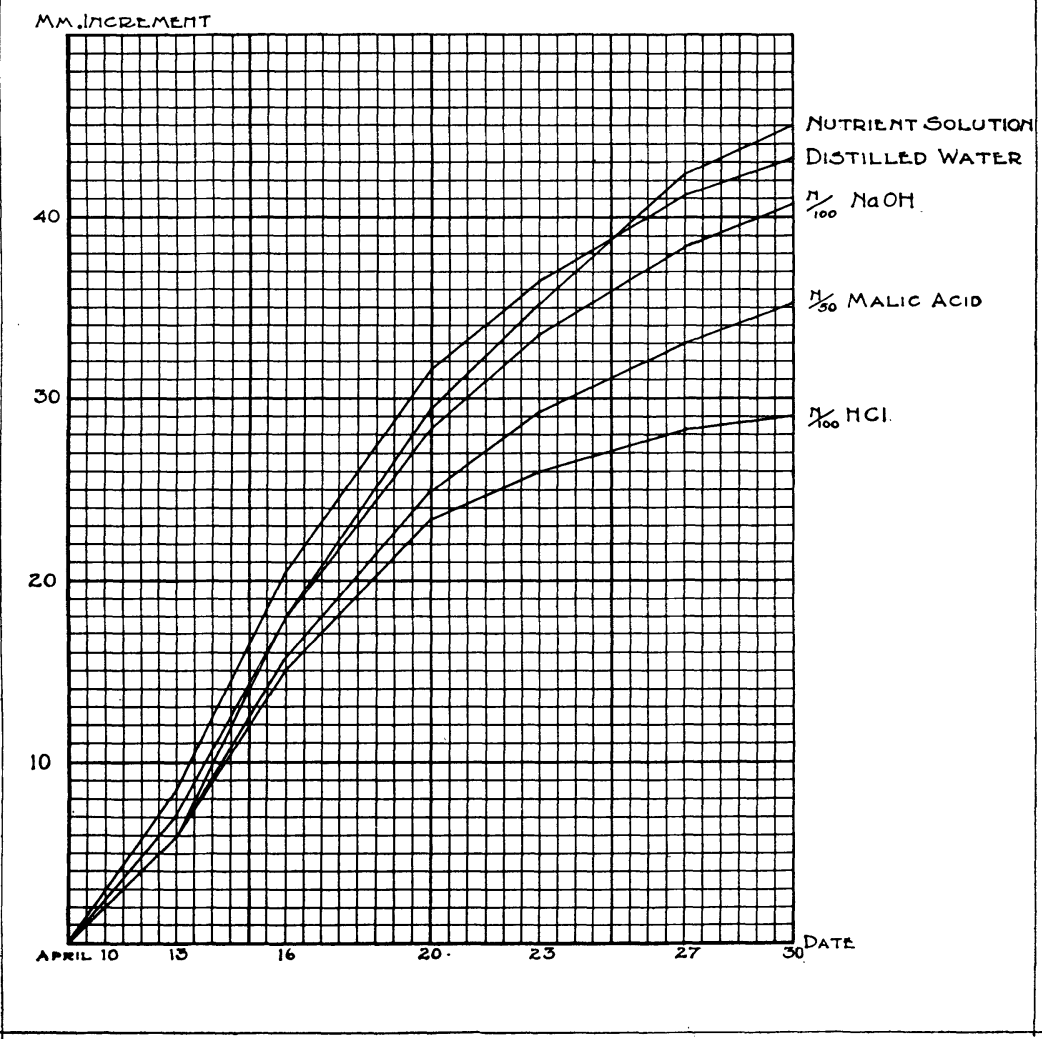

FIG. I.-Growth of new joints of Opuntia Blakeana

BoRowikow's concentrations ranging from $\mathrm{N} /$ ioo to much lower. It might be argued that $\mathrm{N} / 50$ or even $\mathrm{N} /$ roo $\mathrm{HCl}$ could be toxic in other ways than in their effect upon water imbibition. The same could hardly be held, however, concerning $\mathrm{N} / 5^{\circ}$ malic acid, as this is considerably below the concentration of the same acid 
in the cell sap. Nor is it likely that the lower swelling in acid solution is to be accounted for on the ground of osmotic pressure difference. The data in table II will give some idea of the rôle of osmotic pressure in water imbibition in this plant. The figures

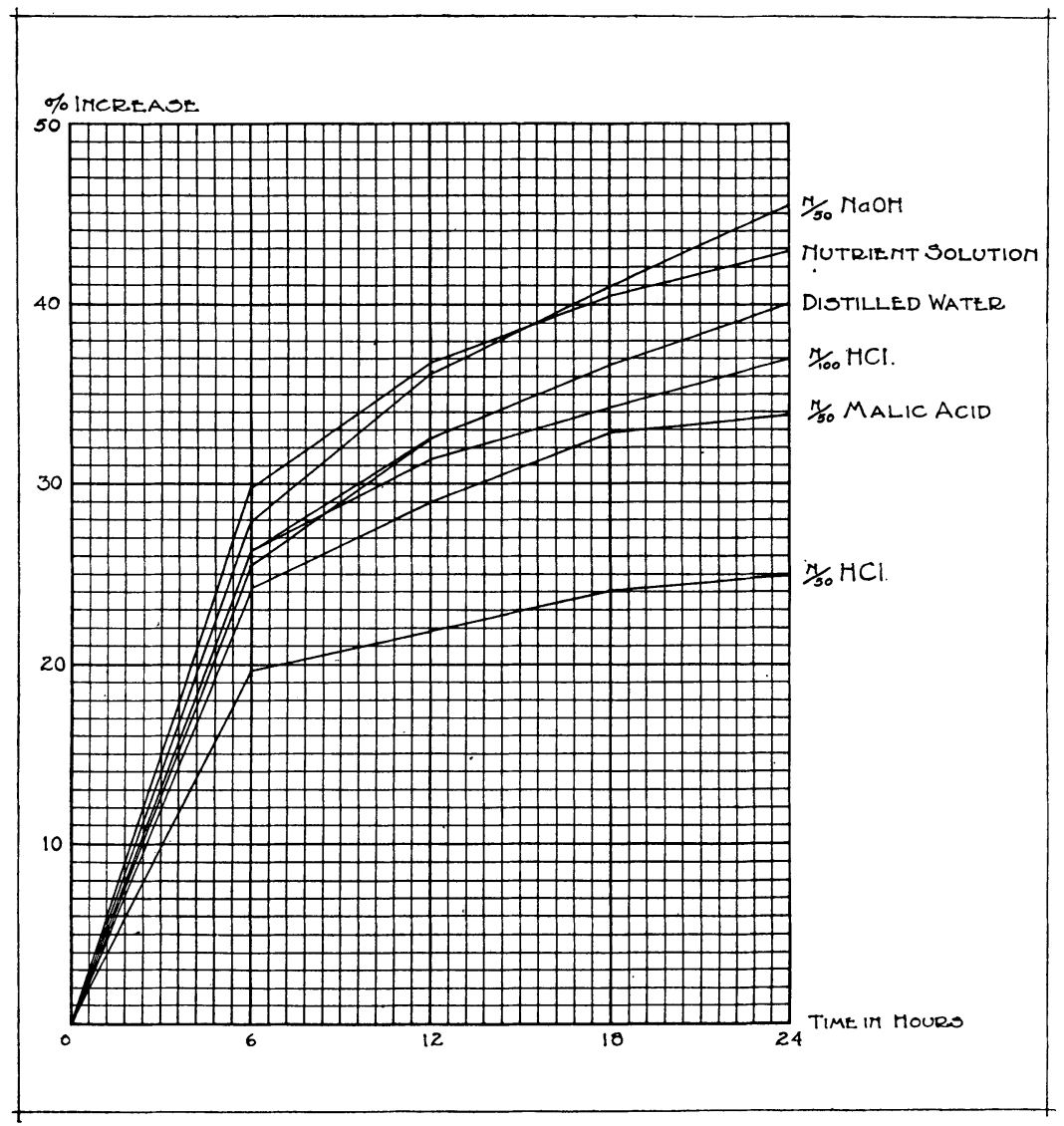

Fig. 2.- - Hydratation of Opuntia Blakeana

given are for four pieces of Opuntia Blakeana in each solution, similar to those used in the hydratation experiments.

As may be seen, the swelling in distilled water and $\mathrm{N} / 50 \mathrm{KNO}_{3}$ is practically the same, the slightly higher osmotic pressure of the latter being without measurable effect as regards increase in weight 
due to imbibed water. It may be assumed that the osmotic pressure of the less ionized malic acid in $\mathrm{N} / 50$ concentration would also be without appreciable effect in the experiments in question.

TABLE II

\begin{tabular}{|c|c|c|c|}
\hline Solution & Wt. at start & Wt. after $24 \mathrm{hrs}$. & Percentage increase \\
\hline 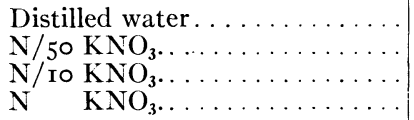 & $\begin{array}{l}\text { I } 7.64 \mathrm{gm} . \\
\text { I } 7.83 \\
\text { I } 5.65 \\
\text { I } 6.75\end{array}$ & $\begin{array}{l}22.59 \mathrm{gm} . \\
22.88 \\
\mathrm{1} 9.40 \\
\mathrm{I} 3.77\end{array}$ & $\begin{array}{r}28.1 \\
28.3 \\
23.9 \\
-17.8\end{array}$ \\
\hline
\end{tabular}

It seems probable, in view of these facts, that the lowered swelling in acid solution is the direct effect of the acid ion upon the colloids which take part in the swelling. The slower growth rate in acid solutions is significant in this connection.

The action of alkalies upon swelling was not so regular in its effect as that of acids. While a swelling of lower degree than that produced in distilled water was practically invariable with acids, the swelling produced in alkalies was sometimes greater and in other cases less than that taking place in distilled water, and no satisfying explanation can be given for this behavior. The varying acidity of the plant itself was perhaps a factor, by neutralizing to a greater or less degree the alkali of the penetrating medium. The curve represents the average of all cases examined.

It is interesting to observe that in nutrient solution, practically always a slightly increased swelling over that taking place in distilled water occurred, and furthermore that this was paralleled, as might be expected, by a greater growth rate in this medium. The mechanism of this action, which took place in a neutral medium, was not determined.

In general, growth and swelling in these experiments paralleled rather closely nutrient solution exerting an accelerating effect over that observed in distilled water, and hydrochloric and malic acids an inhibitory one, while the effect of sodium hydroxide was irregular.

While no attempt was made to separate and determine the colloid constituents of the plant to the presence of which the swelling 
was due, it is evident that substances of much different physical nature from such colloids as gelatin and fibrin, which show a marked increase in swelling in acid solutions, are concerned. It should be noted that common cornstarch (boiled and dried) swells no more in $\mathrm{N} / 50$ and $\mathrm{N} / 25 \mathrm{HCl}$ than in distilled water, although the effect of $\mathrm{NaOH}$ of the same molecular strength in this direction is marked.

One important point left to be considered is the effect of the varying acidity of the plant sap upon the water-absorbing power of the plant. Dr. MacDougal, to whom I am indebted for many suggestions in this work, has observed that the greatest growth rate of Opuntia Blakeana takes place in the day. In the daytime the acidity of the plant sap is on the decrease, the acid products of carbohydrate metabolism, after accumulating during the night, being destroyed by light and increased temperature during the day. ${ }^{3}$ Can it be that this decrease has an effect upon the waterabsorbing power and in consequence upon growth? The following experiment was carried out to test this. A joint of Opuntia Blakeana was cut at 5:00 A.M., $0.75 \mathrm{hr}$. before sunrise, the period of maximum acidity. Four disks were cut from it, and the holes plugged to prevent abnormal evaporation. The swelling of these in one hour in distilled water at $25^{\circ} \mathrm{C}$. in diffuse light was determined immediately. The joint was exposed to the bright sunlight until

TABLE III

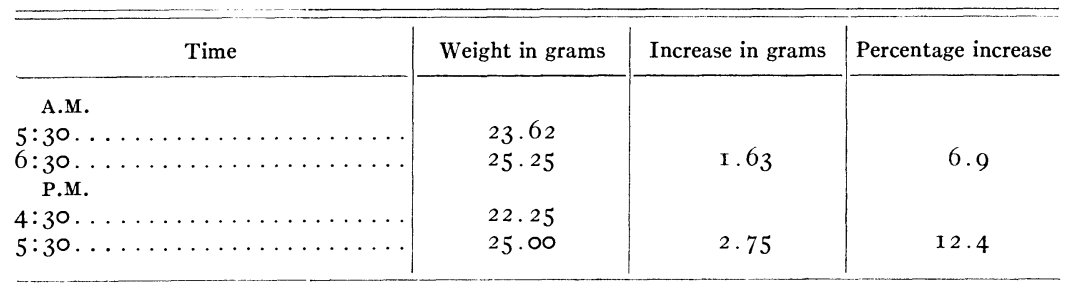

4:00 P.M., the period of minimum acidity, and then four disks were cut and their swelling determined in diffuse light for one hour, also at $25^{\circ} \mathrm{C}$. The results are shown in table III.

${ }^{3}$ Spoenr, H. A., Biochem. Zeitschr. 57 :95-I I I. I9I3. 
The swelling of the less acid sample is much the greater, and the difference is too great to be explained on the ground of increased osmotic pressure due to the day's transpiration. This result corresponds to those recorded above which had to do with pieces of the plant in acid and neutral solutions, and may be interpreted as possibly throwing light on the varying diurnal growth rate.

Desert Laboratory

TuCsON, ARIz. 